GLIA 24:39-49 (1998)

\title{
Intercellular Calcium Waves in Glia
}

\author{
ANDREW CHARLES* \\ Department of Neurology, UCLA School of Medicine, Los Angeles, California
}

KEY WORDS astrocytes; ol igodendrocytes; I $P_{3}$; gap junctions; cortex; hi ppocampus; review

\begin{abstract}
Glial cells are capable of communicating increases in [Ca $\left.{ }^{2+}\right]_{i}$ from a single cell to many surrounding cells. These intercellular $\mathrm{Ca}^{2+}$ waves have been observed in glia in multiple different preparations, including dissociated brain cell cultures, glial cell lines, organotypic brain slice cultures, and intact retinal preparations. They may occur spontaneously, or in response to a variety of stimuli. $\mathrm{Ca}^{2+}$ waves occurring under different conditions in different preparations may have distinctive patterns of initiation and propagation, and distinctive pharmacological characteristics consistent with the involvement of different intracellular and intercellular signaling pathways. This paper presents original data supporting a combination of gap junction and extracellular messenger-mediated signaling in mechanically induced glial $\mathrm{Ca}^{2+}$ waves. Additional new observations provide evidence that a rapidly propagated signal may precede the glial $\mathrm{Ca}^{2+}$ wave and may mediate rapid glial-neuronal communication. This original data is discussed in the context of a review of the literature and current concepts regarding the potential mechanisms, physiological and pathological roles of this dynamic pattern of glial intercellular signaling. GLIA 24:39-49, 1998. @ 1998 Wiley-Liss, Inc.
\end{abstract}

\section{INTRODUCTION}

The function of glial cells involves a high level of intercellular coordination. Fluorescence video imaging has recently provided a dramatic visualization of one mechanism for coordination of glial function: intercellular $\mathrm{Ca}^{2+}$ waves. Increases in $\left[\mathrm{Ca}^{2+}\right]_{i}$ that are propagated in a wavelike fashion from a single cell to many surrounding cells have been observed in multiple glial cell preparations in responseto a variety of stimuli. The $\mathrm{Ca}^{2+}$ waves that occur under different conditions have both similarities and differences in their temporal and spatial characteristics, and it is now clear that there are multiple forms of $\mathrm{Ca}^{2+}$ waves in glia that involve distinct mechanisms of initiation and propagation. $\mathrm{Ca}^{2+}$ waves have al so been reported in a wide variety of other cell types (Sanderson et al., 1994). This paper focuses exclusively on intercellular $\mathrm{Ca}^{2+}$ waves in glial cells, including the role of gap junctions in their communication from cell to cell, messengers involved in their communication, and their potential roles in bi-directional glial neuronal signaling under both physiological and pathological conditions.

\section{MATERIALS AND METHODS Cell Culture}

Primary mixed glial cell cultures were prepared from rat brain using standard techniques as previously described (Charles et al., 1991). In brief, the forebrain was dissected from either 1 day postnatal rats, the meninges were removed, and a cell suspension was obtained by passing the tissue through Nitex mesh. Cells were then plated on glass coverslips in DMEM/ F 12 with $10 \%$ fetal calf serum (FCS) and grown for 7-14 days prior to experimentation. I mmunol abeling of these cultures reveal ed that $40-60 \%$ of cells were astrocytes labeled for GFAP, 10-20\% were oligodendrocytes labeled for GalC, 10-30\% were precursor cells which label ed for A2B 5 but not GalC, and 5-10\% were microglia label ed for esterase (Charles et al., 1991).

Contract grant sponsor: NIH; Contract grant numbers: R29 NS32283, P01 NS02808.

*Correspondence to: Andrew Charles, Department of Neurology, UCLA School of Medicine, 710 Westwood Plaza, Los Angeles, California 90095. E-mail: acharles@ucla.edu

Received 25 J uly 1997; Accepted 16 September 1997 
Primary glial-neuronal cultures were prepared using a modification of the techniques described above. A cell suspension was obtained from embryonic mice (15-17 day gestation), and cells were initially plated on either plastic flasks in DMEM/F 12 with $10 \%$ fetal calf serum (FCS). The flasks were shaken 6-8 $\mathrm{h}$ after initial plating to remove non-adherent cells. The non-adherent cells were then plated onto glass coverslips and grown in DMEM/F 12 supplemented with insulin 5 $\mathrm{mg} / \mathrm{l}$, transferrin $5 \mathrm{mg} / \mathrm{l}$, and sel enium 5 $\mu \mathrm{g} / \mathrm{l}$ (Reduser, U pstate Biotechnology), and 5\% FCS. This resulted in cultures that were initially composed of $50-75 \%$ neurons and $25-50 \%$ glial cells (Charles, 1994). Since no mitotic inhibitors were used, the percentage of glial cells increased progressively with age in culture.

\section{Measurement of $\left[\mathrm{Ca}^{2+}\right]_{i}$}

$\left[\mathrm{Ca}^{2+}\right]_{\mathrm{i}}$ was measured using a fluorescence imaging system that has previously been described in detail (Charles et al., 1991). In brief, cells on glass coverslips were loaded with fura2 by incubation in $5 \mu \mathrm{M}$ fura2-AM for $40 \mathrm{~min}$. Cells were then washed and maintained in normal medium for $30 \mathrm{~min}$ prior to experimentation. Coverslips were placed on a Nikon Diaphot inverted microscope and excited with a mercury lamp through 340 and $380 \mathrm{~nm}$ bandpass filters, and fluorescence at $510 \mathrm{~nm}$ was recorded through a $20 \times$ or $40 \times$ objective with a SIT camera to an optical memory disc recorder. Images were then digitized and subjected to background subtraction and shading correction, after which $\left[\mathrm{Ca}^{2+}\right]_{\mathrm{i}}$ was calculated on a pixel-by-pixel basis as previously described. Data acquisition and analysis software were written by Dr. Michael Sanderson.

\section{RESULTS}

Mechanical stimulation of a single cell in a mixed glial culture in static medium results in a wave of increased $\left[\mathrm{Ca}^{2+}\right]_{\mathrm{i}}$ that spreads from the point of contact of the pipette throughout the stimulated cell (Fig. 1A; Charles et al., 1991). This is followed by concentric propagation of increased $\left[\mathrm{Ca}^{2+}\right]_{\mathrm{i}}$ to neighboring cells that occurs at sites of cell-cell contact and that spreads as waves within individual cells. There is often a delay of $0.5-1 \mathrm{~s}$ between arrival of the wave at the border of one cell and the initiation of the wave in the adjacent cell.

Rapid perfusion of the extracellular medium (up to 20 $\mathrm{ml} / \mathrm{min}$ in a chamber holding $0.5 \mathrm{ml}$ ) alters the temporal and spatial characteristics of mechanically induced $\mathrm{Ca}^{2+}$ waves (Fig. 1B). When a single cell is mechanically stimulated during rapid medium perfusion, the resulting intercellular $\mathrm{Ca}^{2+}$ wave is initially concentric (the first 1-5 cells concentrically in all directions), with the same velocity and the same cell-to-cell pattern as that in static medium. However, after 2-4 s of concentric propagation, the wave then "takes off" at a much higher rate in the direction of perfusion, often skipping cells rather than traveling with the same cell-to-cell pattern. The average number of cells in each direction of the concentric component of the wave, including the direction directly opposite the direction of perfusion, was $2.57 \pm .97(n=12$ experiments on six different cultures). The wave then traveled to at least 8-10 cells further in the direction of perfusion, usually to the edge of the imaged field.

$\mathrm{Ca}^{2+}$ waves induced by mechanical stimulation can be propagated across gaps with no intervening cells. However, we have found that a mechanically-induced $\mathrm{Ca}^{2+}$ wave travels significantly faster and farther in areas of cell contact than in cell-free areas (Fig. 1C). We found that the average maximum velocity across cellfree regions that were $50-100 \mu \mathrm{M}$ wide was $5.43 \mu \mathrm{m} / \mathrm{s}$ $( \pm 1.01 \mu \mathrm{m} / \mathrm{s}$ S.D., $\mathrm{n}=$ ei ght experiments on six different coverslips), whereas the maximum velocity over the same distance in the area where cells were in contact was $11.25 \mu \mathrm{m} / \mathrm{sec}$ ( $\pm 2.93 \mu \mathrm{m} / \mathrm{s}$ S.D). We found that the intercellular wave traveled to a maximal distance of $250 \pm 41 \mu \mathrm{m}$ through areas of contacting cells, compared with a maximum distance of $150 \pm 22 \mu \mathrm{m}$ across a 50-100 $\mu$ m cell free area.

Intercellular $\mathrm{Ca}^{2+}$ waves may be preceded by a rapidly propagated signal that does not in itself induce an increase in $\left[\mathrm{Ca}^{2+}\right]_{i}$ in most cells. In both primary glial-neuronal cultures ( $n=5$ different cultures) and co-cultures of an immortalized glial cell line with the GT1 neuronal cell line $(n=3$ different cultures, data not shown), a pattern of glial-neuronal signaling is observed that suggests that rapid communication may precedetheintercellular $\mathrm{Ca}^{2+}$ wave (Fig. ID). In each of these preparations, mechanical stimulation of a glial cell induces a change in $\left[\mathrm{Ca}^{2+}\right]_{i}$ in distant neurons that precedes by several seconds thearrival of the glial $\mathrm{Ca}^{2+}$ waves at sites of contact with these neurons. This pattern of signaling is observed frequently in co-cultures of

Fig. 1. A: Mechanically-induced $\mathrm{Ca}^{2+}$ wave. Panels represent $\left[\mathrm{Ca}^{2+}\right]$ in field of cells in a mixed glial culture. Mechanical stimulation of a single cell induces an increase in $\left[\mathrm{Ca}^{2+}\right]_{i}$ in the stimulated cell that travels in a concentric pattern, at sites of cell-cell contact, to surrounding cells. Scale of images is $320 \mu \mathrm{m}$ by $300 \mu \mathrm{m}$. B: Mechanicallyinduced $\mathrm{Ca}^{2+}$ wave with extracellular perfusion. In the same culture as depicted in $A$, the extracellular medium is perfused rapidly from the top right to the bottom left of the field. Mechanical stimulation of a single cell induces an intercellular $\mathrm{Ca}^{2+}$ wave that initially travels concentrically as in A. After $2 \mathrm{~s}$, the wave then travels at a higher velocity in the direction of perfusion, without a distinct cell-cell pattern of communication. Scale of images is $320 \mu \mathrm{m}$ by $300 \mu \mathrm{m}$. C: $\mathrm{Ca}^{2+}$ wave propagation across a cell-free gap. In this mixed glial culture imaged at lower power, mechanical stimulation of a single cell on the left side of a cell free gap induces a calcium wave that is propagated throughout a monolayer on the same side as the stimulus. After a delay of $30 \mathrm{~s}$, two cells on the opposite side of the gap show an increase in $\left[\mathrm{Ca}^{2+}\right]_{i}$. The $\mathrm{Ca}^{2+}$ wave travels farther and with a higher maximum velocity through the contacting cells than across the gap. Scale of images is $480 \mu \mathrm{m}$ by $500 \mu \mathrm{m}$. D: Rapid glial-neuronal communication. Neuronal cell bodies in this mixed glial-neuronal culture are outlined in white. Mechanical stimulation of a single glial cell induces an immediate increase in $\left[\mathrm{Ca}^{2+}\right]_{i}$ in a distant group of neurons, which precedes the arrival of the calcium wave that travels through the glial monolayer. This suggests that a rapidly propagated signal precedes the increase in $\left[\mathrm{Ca}^{2+}\right]_{i}$. Scale of images is $380 \mu \mathrm{m}$ by $360 \mu \mathrm{m}$. 

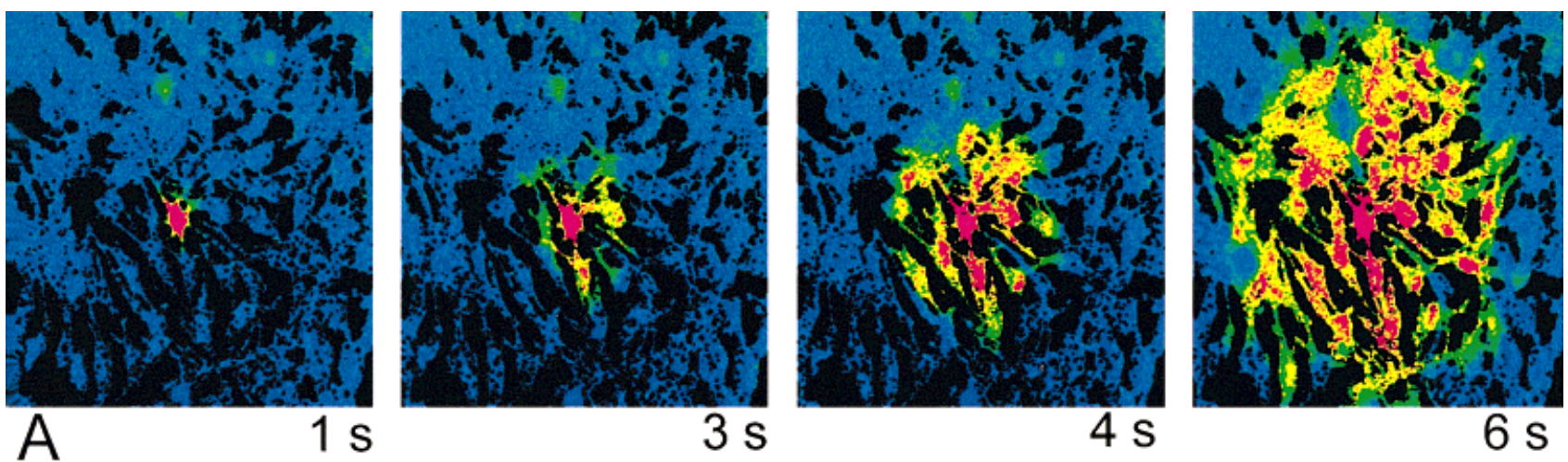

$3 \mathrm{~s}$

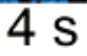

$6 \mathrm{~s}$
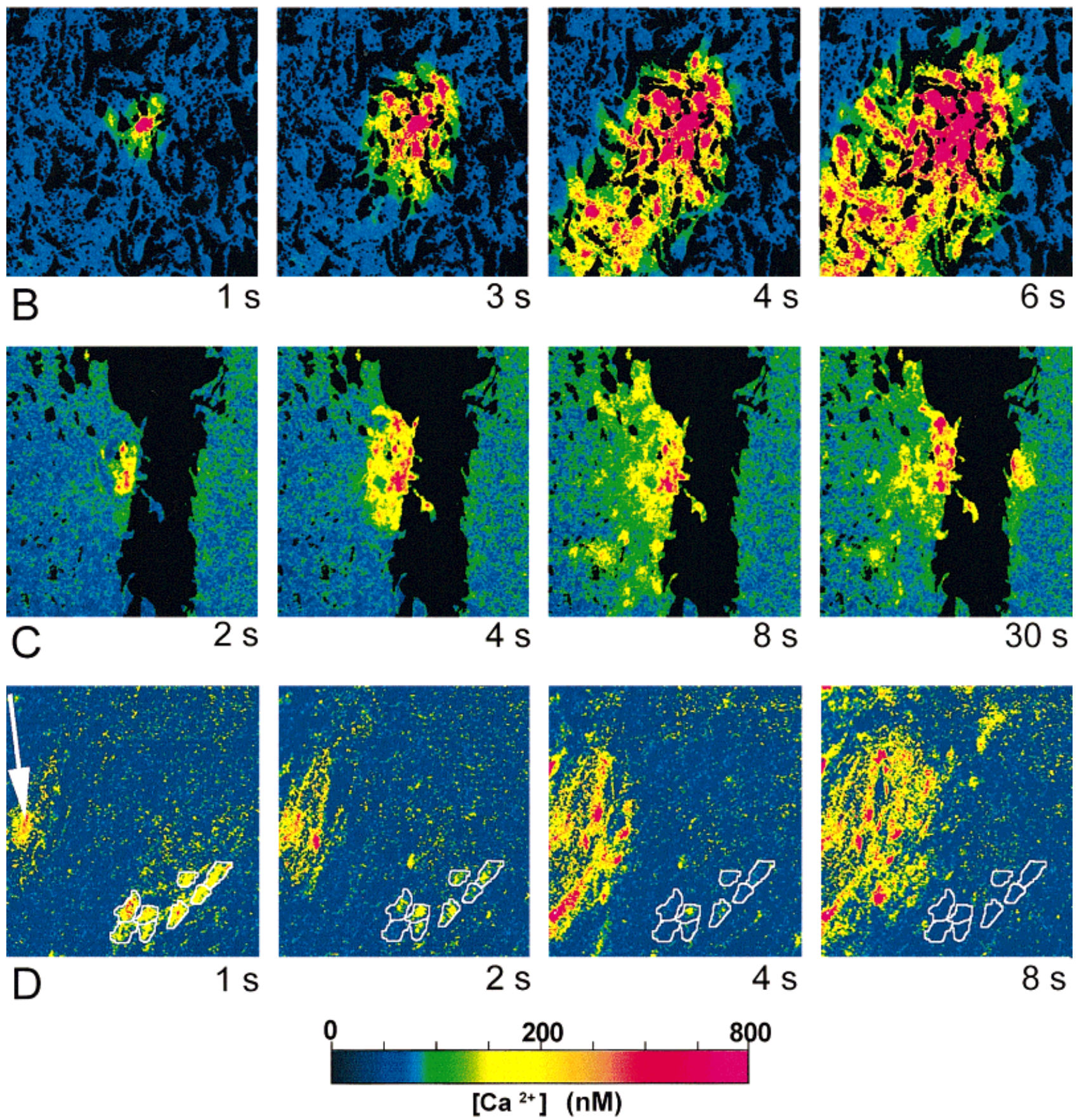
TABLE 1. Descriptions of intercellular calcium waves in gliaa

\begin{tabular}{|c|c|c|c|}
\hline Reference & Preparation & Stimulus & Conclusion \\
\hline Cornell-Bell et al., 1990 & Hippocampal astrocytes & Glutamate & $\begin{array}{l}\text { Intercellular } \mathrm{Ca}^{2+} \text { waves foll lowing bath } \\
\text { application of glutamate }\end{array}$ \\
\hline Charles et al., 1991 & Cortical mixed glia & Mechanical & $\begin{array}{l}\text { Intercellular waves induce sustained asyn- } \\
\text { chronous single-cell } \mathrm{Ca}^{2+} \text { oscillations }\end{array}$ \\
\hline Cornell-Bell and Finkbeiner, 1991 & Hippocampal astrocytes & $\begin{array}{l}\text { Glutamate and glutamate } \\
\text { agonists }\end{array}$ & $\begin{array}{l}\text { Different glutamate receptor subtypes } \\
\text { involved in different } \mathrm{Ca}^{2+} \text { responses }\end{array}$ \\
\hline Charles et al., 1992 & C6 glioma & Mechanical & $\begin{array}{l}\text { Intercellular wave propagation correlated } \\
\text { with level of transfected connexin43 } \\
\text { expression }\end{array}$ \\
\hline Dani et al., 1992 & Hippocampal slice culture & Electrical, NMDA & $\begin{array}{l}\text { Activation of neurons triggers astrocyte } \mathrm{Ca}^{2+} \\
\text { waves }\end{array}$ \\
\hline Enkvist and McCarthy, 1992 & Cortical astrocytes & Mechanical & $\begin{array}{l}\text { Intercellular propagation of } \mathrm{Ca}^{2+} \text { waves } \\
\text { inhibited by activation of protein kinase } \mathrm{C}\end{array}$ \\
\hline Finkbeiner, 1992 & Hippocampal astrocytes & Glutamate & $\begin{array}{l}\text { Intercellular } \mathrm{Ca}^{2+} \text { waves not effected by per- } \\
\text { fusion or gap junction inhibitors }\end{array}$ \\
\hline Charles et al., 1993 & Cortical mixed glia & Mechanical & $\begin{array}{l}\text { Intercellular waves propagated via IP3; } \\
\text { oscillations dependent upon } \mathrm{Ca}^{2+} \text {-induced } \\
\mathrm{Ca}^{2+} \text { release }\end{array}$ \\
\hline Kim et al., 1994 & Hippocampal astrocytes & Glutamate & $\begin{array}{l}\text { Distinguishes metabotropic and ionotropic } \\
\text { waves. I onotropic waves dependent upon } \\
\text { extracellular } \mathrm{Ca}^{2+}\end{array}$ \\
\hline $\begin{array}{l}\text { Charles, } 1994 \\
\text { Nedergaard, } 1994\end{array}$ & $\begin{array}{l}\text { Cortical glia/neuron } \\
\text { Forebrain astrocyte/neuron }\end{array}$ & $\begin{array}{l}\text { Mechanical } \\
\text { Focal el ectrical }\end{array}$ & $\begin{array}{l}\text { Bi-directional glial-neuronal } \mathrm{Ca}^{2+} \text { signaling } \\
\text { Glia-to-neuron communication mediated by } \\
\text { gap junctions }\end{array}$ \\
\hline Parpura et al., 1994 & Cortical astrocyte/neuron & Focal electrical, mechanical & $\begin{array}{l}\text { Glia-to-neuron communication mediated via } \\
\text { astrocytic release of glutamate }\end{array}$ \\
\hline Hassinger et al., 1995 & $\begin{array}{l}\text { Hippocampal astrocyte/ } \\
\text { neuron }\end{array}$ & Electrical & $\begin{array}{l}\text { Glia-to-neuron communication mediated by } \\
\text { ionotropic glutamate receptor channels }\end{array}$ \\
\hline Takeda et al., 1995 & Oligodendrocytes & Mechanical & $\begin{array}{l}\text { Limited intercellular } \mathrm{Ca}^{2+} \text { signaling in puri- } \\
\text { fied oligodendrocytes }\end{array}$ \\
\hline Lee et al., 1995 & Human astrocytes & Glutamate & $\begin{array}{l}\text { Increased intercellular } \mathrm{Ca}^{2+} \text { waves in astro- } \\
\text { cytes from epileptic tissue }\end{array}$ \\
\hline Venance et al., 1995 & Striatal astrocytes & Mechanical, local glutamate & $\begin{array}{l}\text { Intercellular } \mathrm{Ca}^{2+} \text { waves and gap-junctional } \\
\text { communication inhibited by anandamide }\end{array}$ \\
\hline Newman and Zahs, 1997 & Acutely isolated retina & ATP, electrical, mechanical & $\begin{array}{l}\mathrm{Ca}^{2+} \text { waves in astrocytes and } \mathrm{Muller}^{2} \text { cells } \\
\text { dependent on intracellular } \mathrm{Ca}^{2+} \text { stores }\end{array}$ \\
\hline Venance et al., 1997 & Striatal astrocytes & $\begin{array}{l}\text { Mechanical, ionomycin, multiple } \\
\text { ligands }\end{array}$ & $\begin{array}{l}\mathrm{Ca}^{2+} \text { waves induced by multiple ligands } \\
\text { involve } \mathrm{PLC}, \mathrm{IP}_{3} \text {, and gap junctions }\end{array}$ \\
\hline Zanotti and Charles, 1997 & $\begin{array}{l}\text { Cortical mixed glia, } \\
\text { astrocytes }\end{array}$ & Low extracellular $\mathrm{Ca}^{2+}$ & $\begin{array}{l}\text { Extracellular Ca } \mathrm{C}^{2+} \text { sensing by glial cells } \\
\text { evokes intercellular } \mathrm{Ca}^{2+} \text { waves }\end{array}$ \\
\hline Harris-White et al., 1997 & Hippocampal slice cultures & Spontaneous NMDA & $\begin{array}{l}\text { Curvilinear and spiral } \mathrm{Ca}^{2+} \text { waves character- } \\
\text { istic of an excitable medium }\end{array}$ \\
\hline
\end{tabular}

aAll preparations are dissociated cultures unless otherwise stated.

the immortalized glial cell line and the GT1 neuronal cell line, but infrequently (3/20 stimulations in five different cultures) in the primary glial-neuronal cultures. This rapid glial-neuronal signaling is in contrast to the previously reported neuronal response to glial $\mathrm{Ca}^{2+}$ waves, which occurs $0.5-1 \mathrm{~s}$ after the arrival of the glial $\mathrm{Ca}^{2+}$ wave (Charles, 1994).

Intercellular $\mathrm{Ca}^{2+}$ waves induced by mechanical stimulation may induce sustained oscillatory changes in $\left[\mathrm{Ca}^{2+}\right]_{\mathrm{i}}$ in individual cells that continue for as long as 5 min (Fig. 2; Charles et al., 1991). These individual cell $\mathrm{Ca}^{2+}$ oscillations may occur as an intracellular waves, but they are only rarely spread from cell to cell, even in adjacent cells that have just communicated a wave. Therefore, intracellular waves and intercellular waves represent distinct phenomena.

\section{DISCUSSION AND REVIEW Spatial and Temporal Characteristics of $\mathrm{Ca}^{2+}$ Waves}

Intercellular $\mathrm{Ca}^{2+}$ waves in glial cells were first reported by Cornell Bell et al. (1990), who described propagated increases in $\left[\mathrm{Ca}^{2+}\right]_{i}$ in astrocytes from rat hippocampus in response to bath application of glutamate. We subsequently described intercellular $\mathrm{Ca}^{2+}$ waves in mixed glial cultures from rat cortex in response to mechanical stimulation of a single cell (Charles et al., 1991), and similar waves have since been reported in multiple different glial cell preparations in response to a variety of stimuli (Table 1). These different $\mathrm{Ca}^{2+}$ waves have characteristics that indicate distinct mechanisms of propagation. Detailed comparison of glutamate-induced and mechanically induced $\mathrm{Ca}^{2+}$ waves highlights some of these differences.

Upon exposure to glutamate, cultured astrocytes show an initial increase in $\left[\mathrm{Ca}^{2+}\right]_{i}$ that may be communicated as a wave; this has been referred to as a "spatial spike." Then, after a delay of 30-60 s, intercel lular $\mathrm{Ca}^{2+}$ waves propagate from multiple single cell foci to surrounding cells (Kim et al., 1994). By contrast, mechanical stimulation of a single cell in a mixed glial or purified astrocyte culture induces a wave of increased $\left[\mathrm{Ca}^{2+}\right]_{i}$ that travels from the point of stimulation to involve the entire stimulated cell. After a brief delay $(0.5-1 \mathrm{~s})$, the wave is communicated to neighboring cells at points of intercellular contact (Fig. 1A) (Charles 
et al., 1991). Both gl utamate-induced and mechanicallystimulated waves propagate from a single cell to multiple surrounding cells at a velocity of $10-20 \mu \mathrm{m} / \mathrm{sec}$. Under both conditions, the waves are communicated at sites of cell-to-cell contact, and the increase in $\left[\mathrm{Ca}^{2+}\right]_{i}$ often travels as an intracellular wave within individual cells (Charles et al., 1991; Cornell-Bell et al., 1990). However, $\mathrm{Ca}^{2+}$ waves in response to glutamate require extracellular $\mathrm{Ca}^{2+}$ and are communicated without pause at the cell borders (Cornell-Bell et al., 1990; Kim et al., 1994). By contrast, mechanically induced $\mathrm{Ca}^{2+}$ waves show delays at the borders between cells and do not require extracellular $\mathrm{Ca}^{2+}$ (Charles et al., 1991). Thus, although thetemporal and spatial characteristics of the glutamate-induced and mechanically-induced waves are superficially similar, they clearly involve different mechanisms of initiation and propagation.

\section{The Role of Gap J unctions vs. Extracellular Communication}

There is extensive evidence that gap junctions are involved in the propagation of $\mathrm{Ca}^{2+}$ waves between glial cells. The intercellular communication of glutamateinduced $\mathrm{Ca}^{2+}$ waves in astrocytes is blocked by octanol, and the pattern of communication of these waves is not altered by rapid perfusion of the extracellular medium (Finkbeiner, 1992). The intercellular communication of mechanically induced or ionomycin-induced intercellular waves is inhibited by anandamide (Venance et al., 1995) and by 18- $\alpha$-glycyrrhetinic acid (Venance et al., 1997), both of which were shown in parallel experiments to inhibit gap-junctional coupling. C6 glioma cells, which have low levels of connexin expression and low levels of intercellular dye coupling, show limited propagation of intercellular $\mathrm{Ca}^{2+}$ waves induced by mechanical stimulation. By contrast, $\mathrm{C} 6$ cells overexpressing connexin43 show an increased propagation of intercellular $\mathrm{Ca}^{2+}$ waves that is correlated with the level of connexin expression and the level of intercellular dye coupling (Charles et al., 1992).

While these studies strongly support gap junctional communication as one mechanism for communication of $\mathrm{Ca}^{2+}$ waves, they do not rule out other mechanisms. Indeed, the results shown in Figure 1B,C show that $\mathrm{Ca}^{2+}$ waves can also be mediated by an extracellular messenger. Similar findings have been previously reported by Hassinger et al. (1996). Detailed analysis of these experiments is revealing. Both the results presented above and those of Hassinger et al. indicate that there is significant propagation of the wave in the direction opposite perfusion. These results show that there is some component of the response that is not altered by perfusion. In addition, the delay in the perfusion-dependent component of the wave shown in Figure 2B suggests that the initial, concentric multicellular response is required to generate a sufficient concentration of an extracellular messenger to elicit the downstream response. This raises the possibility that
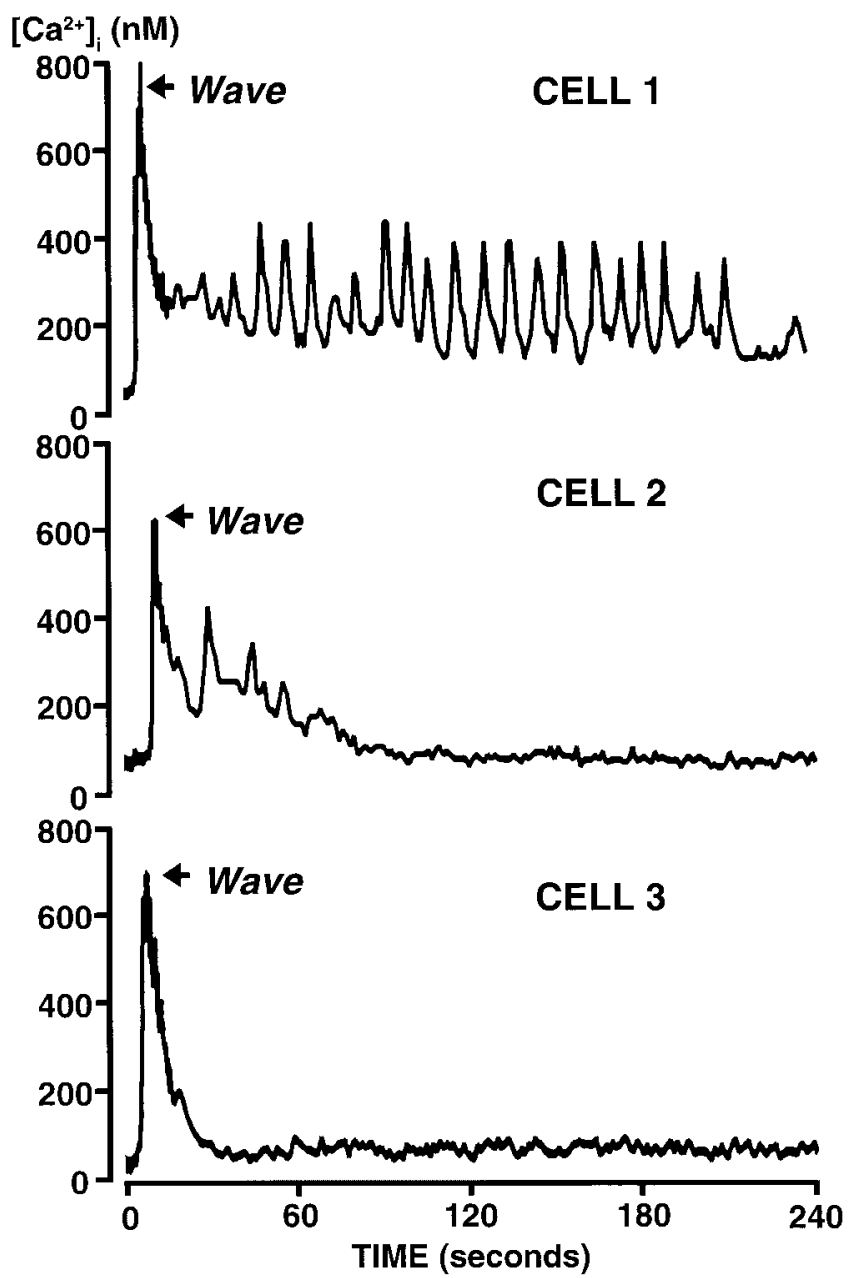

Fig. 2. Patterns of $\left[\mathrm{Ca}^{2+}\right]_{\text {i }}$ responses to a mechanically induced intercellular $\mathrm{Ca}^{2+}$ wave. Tracings represent $\left[\mathrm{Ca}^{2+}\right]_{i}$ in three neighboring cells in a mixed glial culture. The initial peak represents an intercellular $\mathrm{Ca}^{2+}$ wave induced by mechanical stimulation of a nearby cell. Each cell shows a different pattern of oscillations following the wave; these oscillations are asynchronous in individual cells.

$\mathrm{Ca}^{2+}$ waves induced by mechanical stimulation may be initially communicated via gap junctions and subsequently augmented by release of an extracellular messenger. We have also found that intercellular $\mathrm{Ca}^{2+}$ waves induced by low extracellular $\mathrm{Ca}^{2+}$ are biased by perfusion of the medium, providing evidence for the release of an extracellular messenger in response to this stimulus as well (Zanotti and Charles, 1997).

Analysis of the pattern of communication of $\mathrm{Ca}^{2+}$ waves across cell-free regions provides additional information about the role of an extracellular messenger. Hassinger et al. (1996) report that intercellular Ca ${ }^{2+}$ waves induced by electrical stimulation traveled across cell-free lanes in 16 of 35 cases when these lanes were less than $120 \mu \mathrm{m}$ in width, and never crossed when the lane was greater than $120 \mu \mathrm{m}$ in width. In addition, Hassinger et al. (1996) report that the velocity of propagation across cell-free lanes was not significantly different than that across regions of confluent cells. By contrast, the results reported above indicate a signifi- 
Neurotransmitters

Mechanical Stimulation

Low Extracellular $\mathrm{Ca}^{2+}$

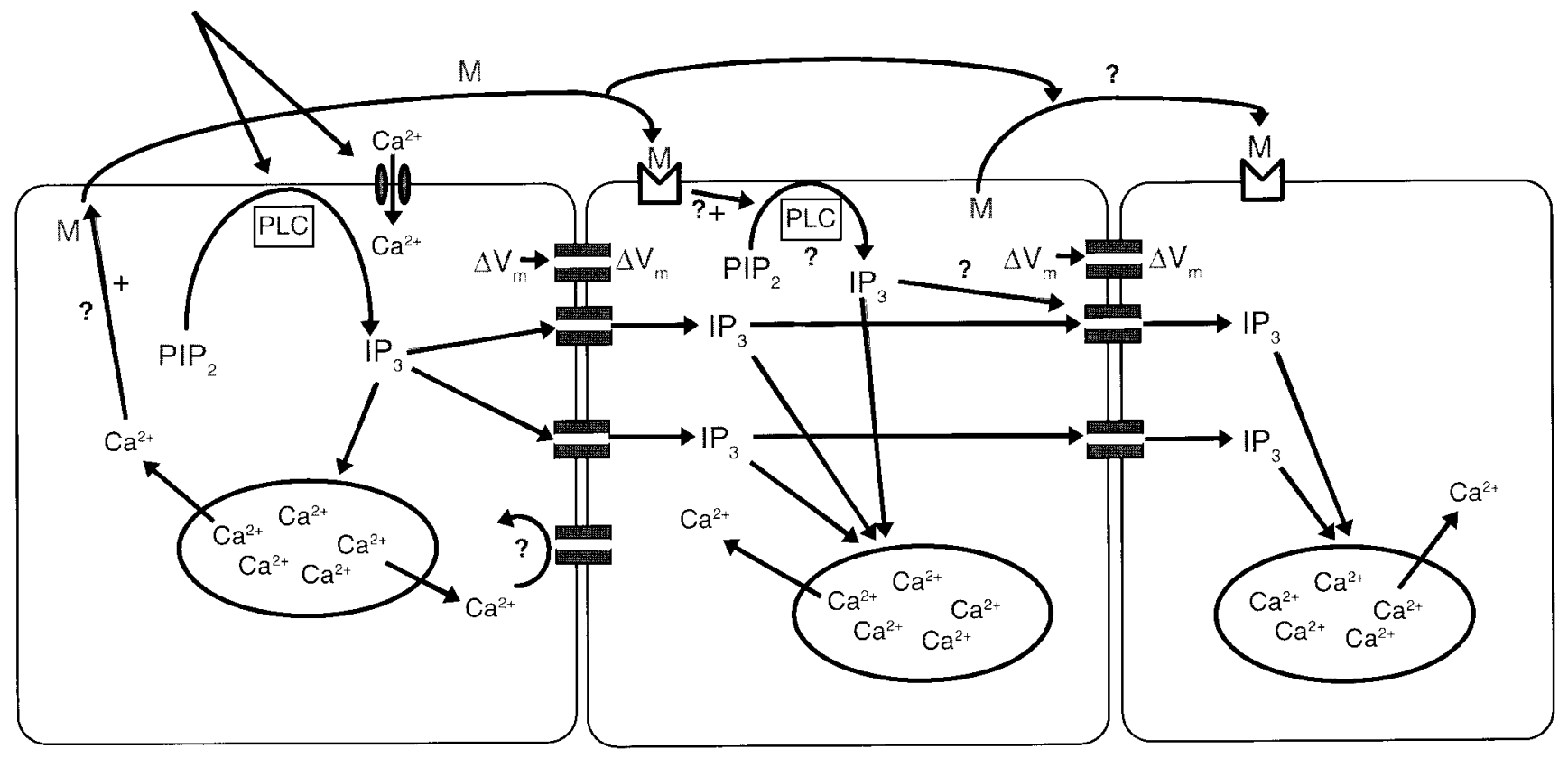

Fig. 3. Schematic model of intercellular $\mathrm{Ca}^{2+}$ waves in glia. The model shows the formation of $I \mathrm{P}_{3}$ in the stimulated cell and the diffusion of $I \mathrm{P}_{3}$ through gap junctions to the adjacent cell. It also shows the release of an extracellular messenger $(\mathrm{M})$ by the stimulated cell. $\mathrm{IP}_{3}$ releases $\mathrm{Ca}^{2+}$ from intracellular stores in both the stimulated and adjacent cells. Other possible mechanisms suggested but less clearly supported by experimental data are indicated by question marks. These include the stimulation of release of the extracellular messen-

cantly higher propagation velocity and distance of propagation in areas of cell contact as compared with cell-free areas. Although the results presented above differ somewhat from those of Hassinger et al., both show that at least some forms of $\mathrm{Ca}^{2+}$ waves in mixed glial cultures may involve an extracellular messenger, and both show that the characteristics of wave propagation are different in areas of cell contact compared with areas of no cell contact. Again, it is likely that a combination of gap junctional communication and release of an extracellular messenger may be involved (Fig. 3).

\section{Intracellular Messengers Involved in Propagation of $\mathrm{Ca}^{2+}$ Waves}

There are multiple potential messengers involved in the communication of $\mathrm{Ca}^{2+}$ waves, and these messengers may act individual ly or in combi nation. Glutamateinduced $\mathrm{Ca}^{2+}$ waves are dependent on extracellular $\mathrm{Ca}^{2+}$; it has been proposed that propagation of these waves involves the sodium-Ca ${ }^{2+}$ exchanger (Kim et al., 1994). By contrast, we and others have reported that mechanically stimulated waves (Charles et al., 1991; Enkvist and McCarthy, 1992; Newman and Zahs, 1997), spontaneous glial intercellular waves in mixed glial- ger by $\mathrm{Ca}^{2+}$, the inability of diffusion of $\mathrm{Ca}^{2+}$ itself to mediate intercellular waves, the role of a change in membrane potential in $\mathrm{Ca}^{2+}$ waves, and the extent to which the propagation of the wave is regenerated by activation of PLC and release of an extracellular messenger by adjacent cells in addition to the stimulated cell. M, extracellular messenger; PLC, phospholipase $\mathrm{C} ; \Delta \mathrm{V}_{\mathrm{m}}$, change in membrane potential.

neuronal cultures or in hippocampal slice cultures (Charles et al., 1991; Harris-White et al., 1997), and low-Ca ${ }^{2+}$-induced intercellular waves (Zanotti and Charles, 1997) do not require extracellular $\mathrm{Ca}^{2+}$. These studies show that some forms of glial $\mathrm{Ca}^{2+}$ waves can be generated entirely by the release of $\mathrm{Ca}^{2+}$ from intracellular stores. Multiple lines of evidence suggest that $\mathrm{Ca}^{2+}$ itself is not the messenger that transmits the response from cell to cell. First, mechanical stimulation in $0 \mathrm{Ca}^{2+}$ medium often does not induce an increase in $\left[\mathrm{Ca}^{2+}\right]_{i}$ in the stimulated cell (possibly due to efflux of $\mathrm{Ca}^{2+}$ through mechanically activated channels), and yet an intercellular $\mathrm{Ca}^{2+}$ wave is still communicated to neighboring cells (Charles et al., 1991). Second, when cells are treated with thapsigargin or the PLC inhibitor U 73122, there is still an increase in $\left[\mathrm{Ca}^{2+}\right]_{i}$ in the stimulated cell, but this increase in $\left[\mathrm{Ca}^{2+}\right]_{i}$ is not propagated to neighboring cells (Charles et al., 1993; Venance et al., 1997). Finally, transient increases in $\left[\mathrm{Ca}^{2+}\right]_{i}$ or oscillatory increases in $\left[\mathrm{Ca}^{2+}\right]_{i}$ may occur in individual glial cells that reach levels that are equal in amplitude to those seen with intercellular $\mathrm{Ca}^{2+}$ waves, and yet there is no communication of these increases in $\left[\mathrm{Ca}^{2+}\right]_{i}$ from cell to cell (Charles et al., 1991; CornellBell et al., 1990). These same cells showing nonpropagating increases in $\left[\mathrm{Ca}^{2+}\right]_{i}$ can participate in propagated intercellular $\mathrm{Ca}^{2+}$ waves in response to 
mechanical stimulation or glutamate. These results indicate that either there is a different level of conductance of the gap junction channel under the circumstances of asynchronous $\mathrm{Ca}^{2+}$ increases vs. communicated intercellular $\mathrm{Ca}^{2+}$ waves, or that $\mathrm{Ca}^{2+}$ itself is not the primary messenger for intercellular communication of the waves.

Theinhibition of $\mathrm{Ca}^{2+}$ wave propagation by thapsigargin and $U 73122$ provide evidence that $I P_{3}$ is required for intercellular communication of glial $\mathrm{Ca}^{2+}$ waves. In tracheal epithelial cells, microinjection of $\mathrm{IP}_{3}$ in a single cell induces intercellular $\mathrm{Ca}^{2+}$ waves similar to those observed in glia (Sanderson et al., 1990) and intercellular propagation of $\mathrm{Ca}^{2+}$ waves is blocked by intracellular heparin (an antagonist of the $\mathrm{IP}_{3}$ receptor) in both tracheal epithelial cells (Boitano et al., 1992) and retinal glia (Newman and Zahs, 1997). These studies provide evidence that $I P_{3}$ is a primary messenger involved in the communication of $\mathrm{Ca}^{2+}$ waves. Mathematical modeling of $\mathrm{Ca}^{2+}$ waves generated by the diffusion of IP3 through gap junctions predicts spatial and temporal patterns of $\mathrm{Ca}^{2+}$ signals that are very similar to experimental data from glial cultures (Sneyd et al., 1994, 1995). However, as discussed above, receptor-mediated formation of $\mathrm{IP}_{3}$ induced by an extracellular messenger may also play a primary role, or augment the diffusion of $I P_{3}$ through gap junctions.

The rapid communication of a response from a mechanically stimulated glial cell to distant neurons shows that a signal may be propagated through glial cells that precedes the $\mathrm{Ca}^{2+}$ wave. While it is possible that this rapid communication occurs via neuronal processes that are not visible by phase-contrast or fluorescence microscopy, another possi bility is that a rapidly communicated signal, such as a depolarization spread el ectrotonically via gap junctions, induces a $\mathrm{Ca}^{2+}$ response in neighboring neurons but not in glial cells. This mechanism would indicate the occurrence of gap junctional coupling between at least a subset of glia and neurons (see below). Newman and Zahs (1997) reported that el ectrical and mechanical stimulation of a single astrocyte in the intact retina induced depolarizations as great as $37 \mathrm{mV}$ in distant astrocytes as measured in the whole-cell current-clamp configuration. Consistent with the observations reported here, these depolarizations either preceded arrival of a $\mathrm{Ca}^{2+}$ wave or occurred when waves did not reach the cell that showed a depolarization. Enkvist et al. (1993) reported that depolarization of cells with $50 \mathrm{mM}$ extracellular $\mathrm{K}$ did not induce an increase in $\left[\mathrm{Ca}^{2+}\right]_{i}$ in glia in their preparation and also did not alter intercellular communication of mechanically induced $\mathrm{Ca}^{2+}$ waves. These results, as well as those of Newman et al., show that a change in membrane potential is not directly responsible for a communicated increase in $\left[\mathrm{Ca}^{2+}\right]_{\mathrm{i}}$. However, Enkvist et al. (1994) also showed that depolarization increased dye coupling in glial cells. It is therefore possible that a propagated depolarization could somehow "prime" cells for the communication of $\mathrm{Ca}^{2+}$ waves.

\section{Possible Extracellular Messengers I nvolved In $\mathrm{Ca}^{2+}$ Waves}

As discussed above, an extracellular messenger may play a role in the intercellular communication of glial $\mathrm{Ca}^{2+}$ waves induced by multiple stimuli. Several candidates for this extracellular messenger have been studied, but none has been definitively shown to mediate glial $\mathrm{Ca}^{2+}$ wave communication. Purine nucleotides have been identified as an extracellular messenger in a variety of cell types (E nomoto et al., 1994; Frame and de Feijter, 1997; Osipchuk and Cahalan, 1992), and there is some evidence that they may play a role in glial $\mathrm{Ca}^{2+}$ waves. Suramin, a purinergic receptor antagonist, inhibits the extent of intercellular communication of mechanically-induced propagation of glial $\mathrm{Ca}^{2+}$ waves at high concentrations (50-100 $\mu \mathrm{M}$, data not shown). But the actions of this agent are not specific, and therefore they are not conclusive. The ATP agonist 2-methylthio-ATP inhibits intercel lular communication of mechanically-induced $\mathrm{Ca}^{2+}$ waves, an effect that might be due to desensitization of ATP receptors, or as the authors suggest, to activation of PKC (Enkvist and McCarthy, 1992). Evidence against ATP as a messenger for $\mathrm{Ca}^{2+}$ waves is provided by Venance et al. (1995), who reported that the ATP- degrading enzyme apyrase does not alter the intercellular communication of waves. Another potential extracellular messenger is glutamate. Parpura et al. (1995) have shown that there is a $\mathrm{Ca}^{2+}$-dependent release of glutamate from astrocytes that mediates glial-neuronal signaling. However, we have found that $\mathrm{Ca}^{2+}$ waves induced by mechanical stimulation can occur in high concentrations of glutamate, suggesting that saturation of the receptor does not affect the waves (Charles et al., 1991). In addition, multiple investigators have shown that $\mathrm{Ca}^{2+}$ waves induced by mechanical, electrical, and receptor-mediated stimulation are not blocked by glutamate receptor antagonists (Charles et al., 1991; Enkvist and McCarthy, 1992; Hassinger et al., 1996; Parpura et al., 1994; Venance et al., 1997). While these results do not exclude a role for glutamate in $\mathrm{Ca}^{2+}$ wave propagation, they suggest that glutamate receptors are not essential for this process. Another possibility is that glutamate may evoke $\mathrm{Ca}^{2+}$ signaling through a glutamate transportermediated mechanism. There are multiple other candidates for extracellular messengers involved in glial $\mathrm{Ca}^{2+}$ waves, and it is possible that more than one may beinvolved.

\section{Intracellular $\mathrm{Ca}^{2+}$ Waves Are Distinct From I ntercellular $\mathrm{Ca}^{2+}$ Waves}

The simultaneous occurrence of oscillatory intracellular $\mathrm{Ca}^{2+}$ waves and propagated intercellular $\mathrm{Ca}^{2+}$ waves suggests that $\mathrm{Ca}^{2+}$ itself is not the messenger that mediates propagation of intercellular $\mathrm{Ca}^{2+}$ waves. Based upon the effects of thapsigargin and dantrolene, we have proposed that IP3 is the messenger that 
mediates intercel lular communication of waves, whereas $\mathrm{Ca}^{2+}$-induced $\mathrm{Ca}^{2+}$ release mediates subsequent singlecell oscillations (Charles et al., 1993). Mathematical modeling based upon IP3 as the messenger that mediates intercellular propagation of $\mathrm{Ca}^{2+}$ waves yields multiple patterns of cellular $\mathrm{Ca}^{2+}$ oscillations that occur based upon the distance of each cell from the stimulated cell; these patterns are highly consistent with experimental data shown in Fure 2 (Sneyd et al., 1994).

An important implication of the multiple patterns of transient or sustained $\mathrm{Ca}^{2+}$ oscillations induced by a single $\mathrm{Ca}^{2+}$ wave is that the response of each cell to a wave may have strikingly different characteristics. This may represent a mechanism for individual cells to respond to a common stimulus with distinct patterns of signaling. The amplitude, frequency, and duration of the $\mathrm{Ca}^{2+}$ response in individual cells may encode both spatial and temporal information based upon the location and type of the original stimulus.

\section{The Role of $\mathrm{Ca}^{2+}$ Waves in Glial-Neuronal Signaling}

In addition to providing a mechanism for signaling between glia, intercellular $\mathrm{Ca}^{2+}$ waves may al so represent a pathway for signaling between glia and neurons. Glial cells in mixed culture or purified astrocyte or oligodendrocyte culture show occasional spontaneous single-cell oscillations, and rare intercellular waves that are limited to a few cells. By contrast, glial cells in culture with neurons show frequent spontaneous oscillations as well as more frequent and more extensive intercellular waves (Charles, 1994). The waves often appear to be initiated at sites of contact with neurons, suggesting that they may be initiated by neuronal-glial communication. However, this glial signaling is not blocked by TTX, showing that ongoing neuronal activity is not required to initiate the process. Dani et al. (1992) have shown that glial $\mathrm{Ca}^{2+}$ signaling can be induced by NMDA and stimulation of neuronal pathways in hippocampal slice cultures. We have made similar observations in hippocampal slice cultures, where spiral intercellular $\mathrm{Ca}^{2+}$ waves occurring predominantly in astrocytes are induced by bath application of NMDA (Harris-Whiteet al., 1997). These studies indicate that $\mathrm{glial} \mathrm{Ca}^{2+}$ waves can be evoked by neuronal activity.

Conversely, multiple investigators have also found that glial $\mathrm{Ca}^{2+}$ waves can induce changes in neuronal activity (Charles, 1994; Hassinger et al., 1995; Nedergaard, 1994; Parpura et al., 1994). Nedergaard (1994) provides evidence that this signaling between neurons and glial cells occurs via gap junctions. Parpura et al. (1994) provide evidence that glia-to-neuron signaling is mediated by $\mathrm{Ca}^{2+}$-induced release of glutamate. The observations of Hassinger et al. (1995) are consistent with the latter mechanism. As discussed above, we have observed different patterns of glia-to neuron signal- ing suggesting that both may occur. In both primary neuron-glia cultures from mouse cortex, and in cocultures of neuronal and glial cell lines, we observe both rapid and del ayed response of neurons to $\mathrm{Ca}^{2+}$ waves in glia. In the rapid response, the neurons respond to mechanical stimulation of a distant glial cell almost instantaneously, beforearrival of the glial $\mathrm{Ca}^{2+}$ waveas described above (Fig. 1D). In the delayed pattern of response, the neuron responds $0.5-2 \mathrm{~s}$ after the $\mathrm{Ca}^{2+}$ wave has arrived to glia immediately adjacent to the neuron. One possible explanation for these distinct temporal patterns of glial-neuronal signaling is that the rapid neuronal response is mediated by depolarization that is spread electronically via gap junctions between glia and neurons, whereas the delayed response is mediated by glial release of an extracellular messenger. Another interesting observation is that spontaneous, single glial cell $\mathrm{Ca}^{2+}$ transients rarely if ever induce increases in [ $\left.\mathrm{Ca}^{2+}\right]_{i}$ in neighboring neurons, whereas multicellular $\mathrm{Ca}^{2+}$ waves reliably induce increases in $\left[\mathrm{Ca}^{2+}\right]_{i}$ in neurons. This discrepancy suggests either distinct messengers, or different concentrations of messengers involved in the single-cell $\mathrm{Ca}^{2+}$ transients vs. the multicellular $\mathrm{Ca}^{2+}$ waves.

\section{Are Glial $\mathrm{Ca}^{2+}$ Waves an Artifact Of Cell Culture?}

A question that is frequently raised regarding glial $\mathrm{Ca}^{2+}$ waves is the extent to which they occur in the intact nervous system. Technical limitations have prevented a definitive answer to this question. However, recent observations in in vitro preparations with preserved cellular architecture, as well as the correlation of the temporal and spatial characteristics of glial $\mathrm{Ca}^{2+}$ signaling with patterns of activity in the intact brain provide indirect evidence for glial $\mathrm{Ca}^{2+}$ waves in vivo. The studies by N ewman and Zahs (1997) clearly demonstrate the occurrence of $\mathrm{glial} \mathrm{Ca}^{2+}$ waves in an intact acute retinal preparation that has not been maintained in culture. We and others (Dani et al., 1992; HarrisWhite et al., 1997) have observed intercellular $\mathrm{Ca}^{2+}$ waves in glial cells in hippocampal slice culture preparations in which the typical cellular architecture of the hippocampus is preserved. These studies, while involving slices maintained in culture, do show that intercellular $\mathrm{Ca}^{2+}$ waves are not an artifact of dissociation of cells.

Although spatially resolved visualization of cellular $\left[\mathrm{Ca}^{2+}\right]$ in intact brain preparations has not yet been achieved, studies using laser-doppler imaging, optical intrinsic signal imaging, PET imaging, and EEG techniques have identified changes in blood flow, metabolism, and electrical activity that are propagated with vel ocity and spatial patterns that are similar to those of glial $\mathrm{Ca}^{2+}$ waves observed in culture preparations (Woods et al., 1994; Busch et al., 1995; Lauritzen and Fabricius, 1995). As discussed below, these similarities raise the possibility that glial $\mathrm{Ca}^{2+}$ waves are involved 
in patterns of signaling in the intact brain observed with other techniques.

\section{Potential Physiological Roles of Glial Ca ${ }^{2+}$ Waves}

No physiological role for glial $\mathrm{Ca}^{2+}$ waves has been clearly established. However given that an increase in $\left[\mathrm{Ca}^{2+}\right]_{\mathrm{i}}$ in glial cells may activate ion channels, trigger the release of neuromodulators or trophic factors, or induce changes in glial gene expression, it is easy to speculate that glial $\mathrm{Ca}^{2+}$ waves may provide temporal and spatial coordination for these functions. The most immediate question is whether glial $\mathrm{Ca}^{2+}$ waves influence neuronal excitability and synaptic activity in vivo. As discussed above, there is now strong evidence that bi-directional glial-neuronal signaling involving glial $\mathrm{Ca}^{2+}$ waves occurs in culture preparations. If glial $\mathrm{Ca}^{2+}$ waves have similar effects on neuronal activity in vivo, they may represent a mechanism for modulation of neuronal excitability and synaptic signaling that is slow, sustained, spatially organized, and distinct from traditional synaptic interactions.

Regulation of the extracellular environment, particularly extracel lular $\left[\mathrm{K}^{+}\right]$, is a function that has traditionally been ascribed to glial cells (J anigro et al., 1997; Karwoski et al., 1989; Odette and Newman, 1988; Reichenbach, 1991). $\mathrm{Ca}^{2+}$ waves might provide a mechanism for the "spatial buffering" of $\mathrm{K}^{+}$. A problem with this hypothesis, however, is that an increase in glial $\left[\mathrm{Ca}^{2+}\right]_{\mathrm{i}}$ could also lead to an increase in extracellular $\mathrm{K}^{+}$, due to opening of $\mathrm{Ca}^{2+}$-activated $\mathrm{K}^{+}$channels and subsequent efflux of $\mathrm{K}^{+}$; such a mechanism might be involved in spreading depression (see below). Another important ionic component of the extracellular environment is $\mathrm{Ca}^{2+}$. We have recently found that glial cells respond to lowered extracellular $\mathrm{Ca}^{2+}$ with intercellular $\mathrm{Ca}^{2+}$ waves that invol ve the rel ease of an extracellular messenger (Zanotti and Charles, 1997). We have proposed that this extracellular $\mathrm{Ca}^{2+}$ sensing response of glial cells may occur in the setting of excessive neuronal activity, ischemia, or hypoglycemia, where there is a significant decrease in $\left[\mathrm{Ca}^{2+}\right]$ of the extracellular space (Kristian et al., 1993; Lucke et al., 1995; Puka-Sundvall et al., 1994; Silver and E recinska, 1992).

Glial $\mathrm{Ca}^{2+}$ waves may also play a role in the growth and development of the nervous system. The observation that the extent of propagation of intercellular $\mathrm{Ca}^{2+}$ waves in C6 glioma cells overexpressing connexin43 is directly correlated with their rate of proliferation suggests that intercellular $\mathrm{Ca}^{2+}$ signaling may be involved in the regulation of glial cell proliferation (Charles et al., 1992). Most of the primary preparations in which glial cell $\mathrm{Ca}^{2+}$ waves have been studied are derived from embryonic, perinatal, or immature animals. It is therefore possible that this pattern of signaling is involved in the establishment of the cellular characteristics and connections of the mature nervous system. Yuste and Katz (1995) and Kandler and Katz (1995) have reported spontaneous intercellular $\mathrm{Ca}^{2+}$ waves in groups of neurons in the developing cortex, and have suggested that these "domains" of neurons are involved in the establishment of the functional cellular architecture of the cortex. We have observed repetitive, spontaneous, intercellular $\mathrm{Ca}^{2+}$ waves in groups of glial cells in both dissociated cortical glial-neuronal cultures (Charles, 1994) as well as in hippocampal slice cultures (Harris-White et al., 1997). It is therefore possible that there may also be "domains" of glial cells that are involved in the development of the cellular architecture of the nervous system.

Several studies suggest that the intercellular communication of glial $\mathrm{Ca}^{2+}$ waves may be a target for endogenous signaling molecules in the nervous system. Venance et al. (1995) report that anandamide, an endogenous arachidonic acid derivative that is known to act on cannabinoid receptors, inhibits intercellular coupling and intercellular $\mathrm{Ca}^{2+}$ waves in glia. Enkvist and McCarthy (1994) have shown that gap junctional coupling in glia can be altered by exposure to glutamate. Although the functional consequences of these effects on glial intercellular signaling remain uncertain, these studies demonstratethat transmitters whose conventional effects occur through activation of neuronal receptors may also act to modulate glial intercellular $\mathrm{Ca}^{2+}$ signaling.

\section{Potential Pathological Roles for Glial $\mathrm{Ca}^{2+}$ Waves}

A variety of pathological processes in the brain involve slowly propagated changes in activity whose temporal and spatial characteristics are similar to glial $\mathrm{Ca}^{2+}$ waves. As discussed above, the possibility that glial $\mathrm{Ca}^{2+}$ waves might trigger a propagated change in extracellular ionic concentrations or a propagated release of a neurotransmitter or vasoactive agent provides a hypothetical basis for $\mathrm{Ca}^{2+}$ waves in these phenomena. Spreading depression is a propagated excitation followed by a sustained decrease in neuronal activity that may occur in response to a variety of stimuli, including many of the stimuli that initiate glial $\mathrm{Ca}^{2+}$ waves (Leao, 1944; Somjen, 1992). Spreading depression propagates at rates of $20-60 \mu \mathrm{m} / \mathrm{sec}$, which is very close to the rates that have been described for glial $\mathrm{Ca}^{2+}$ waves. Spreading depression is blocked by inhibitors of gap junctional communication, raising the possibility that gap junctional signaling between glial cells is involved (Largo et al., 1997; Nedergaard et al., 1995). Additional evidence for a link between spreading depression and glial signaling is the observation that repetitive spreading depression induces changes in GFAP expression in astrocytes (Kraig et al., 1991). Potential mechanisms by which glial $\mathrm{Ca}^{2+}$ waves might mediate spreading depression include a propagated increase in extracellular [ $\mathrm{K}^{+}$] or a propagated rel ease of glutamate. However, Largo et al. (1997) also report that fluoroacetate, an inhibitor of glial metabolism, does not 
inhibit spreading depression, and therefore conclude that glial activity is not required.

Seizures are characterized by excessive neuronal activity that in some cases propagates slowly from a single focus across multipleterritories of normal synaptic connections. The pattern of seizure spread, like that of spreading depression, may in some instances be very similar to that of glial $\mathrm{Ca}^{2+}$ waves (Adam et al., 1994; Federico and MacVicar, 1996). Lee et al . (1995) reported that gl utamate-induced $\mathrm{Ca}^{2+}$ oscillations and intercelIular $\mathrm{Ca}^{2+}$ waves were more frequent in tissue from epileptic foci as compared with surrounding tissue.

Migraine is another condition that involves wave-like propagation of changes in cellular activity. Migraine aura involves slowly propagated changes in neuronal activity that may be related to spreading depression (Lauritzen, 1994). A decrease in blood flow that spreads sl owly across multi ple vascular and synaptic territories has been observed in association with migraine (Woods et al., 1994). Since glial cells are known to release vasoactive substances, it is reasonable to suggest that glial $\mathrm{Ca}^{2+}$ waves might trigger the propagated release of a vasoactive substance that mediates the spreading hypoperfusion observed in migraine.

Glial $\mathrm{Ca}^{2+}$ waves may also play a role in the cellular response to injury in the nervous system. Injury of a single cell consistently evokes intercellular $\mathrm{Ca}^{2+}$ waves in glial cells in multiple different preparations. This communicated $\mathrm{Ca}^{2+}$ response may therefore coordinate a multicellular response to a localized injury, including release of cytokines and trophic factors, changes in gene expression, and changes in cell morphology.

\section{CONCLUSIONS}

Intercellular $\mathrm{Ca}^{2+}$ waves are now well established as a pattern of glial cell communication that occurs in response to a variety of stimuli and that may involve multiple mechanisms of inter-and intra-cellular signaling. Current investigation is focused upon the extent to which these waves occur in the intact and the mature brain and spinal cord, and upon their various possible physiological and pathological roles. An increased understanding of this novel pattern of signaling has the potential to provide profound insights into the cellular function of the nervous system.

\section{ACKNOWLEDGMENTS}

This work was supported by NIH R29 NS32283 and P01 NS02808 toA.C.C.

\section{REFERENCES}

Adam, C., Saint-Hilaire, J .M., and Richer, F. (1994) Temporal and spatial characteristics of intracerebral seizure propagation: Predictive value in surgery for temporal lobe epilepsy. Epilepsia, 35: 1065-1072.
Boitano, S., Dirksen, E.R., and Sanderson, M.J . (1992) Intercellular propagation of calcium waves mediated by inositol trisphosphate. Science, 258:292-295.

Busch, E., Hoehn-Berlage, M., Eis, M., Gyngell, M.L., and Hossmann, K.A. (1995) Simultaneous recording of EEG, DC potential and diffusion-weighted NMR imaging during potassium induced cortical spreading depression in rats. NMR Biomed, 8:59-64.

Charles, A.C. (1994) Glia-neuron intercellular calcium signaling. Dev. Neurosci., 16:196-206.

Charles, A.C., Dirksen, E.R., Merrill, J .E., and Sanderson, M.J . (1993) Mechanisms of intercellular calcium signaling in glial cells studied with dantrolene and thapsigargin. Glia, 7:134-145.

Charles, A.C., Merrill, J .E., Dirksen, E.R., and Sanderson, M.J . (1991) Intercellular signaling in glial cells: Calcium waves and oscillations in response to mechanical stimulation and glutamate. Neuron, 6:983-992.

Charles, A.C., Naus, C.C., Zhu, D., Kidder, G.M., Dirksen, E.R., and Sanderson, M.J. (1992) Intercellular calcium signaling via gap junctions in glioma cells. J . Cell. Biol., 118:195-201.

Cornell-Bell, A.H. and Finkbeiner, S.M. (1991) Ca2+ waves in astrocytes. Cell Calcium, 12:185-204.

Cornell-Bell, A.H., Finkbeiner, S.M., Cooper, M.S., and Smith, S.J . (1990) Glutamate induces calcium waves in cultured astrocytes: Long-range glial signaling. Science, 247:470-473.

Dani, J .W., Chernjavsky, A., and Smith, S.J . (1992) Neuronal activity triggers calcium waves in hippocampal astrocyte networks. Neuron, 8:429-440.

Enkvist, M.O. and McCarthy, K.D. (1992) Activation of protein kinase $C$ blocks astroglial gap junction communication and inhibits the spread of calcium waves. J . Neurochem., 59:519-526.

Enomoto, K., Furuya, K., Yamagishi, S., Oka, T., and Maeno, T. (1994) The increase in the intracellular $\mathrm{Ca} 2+$ concentration induced by mechanical stimulation is propagated via release of pyrophosphorylated nucleotides in mammary epithelial cells. Pflugers Arch., 427:533-542.

Federico, P. and MacVicar, B.A. (1996) Imaging the induction and spread of seizure activity in the isolated brain of the guinea pig: the roles of GABA and glutamate receptors. J. Neurophysiol., 76: 3471-3492.

Finkbeiner, S. (1992) Calcium waves in astrocytes-filling in the gaps. Neuron, 8:1101-1108.

Frame, M.K. and de Feijter, A.W. (1997) Propagation of mechanically induced intercellular calcium waves via gap junctions and ATP receptors in rat liver epithelial cells. Exp. Cell Res., 230:197-207.

Harris-White, M.E., Zanotti, S.A., Frautschy, S.A., and Charles, A.C. (1997) Spiral intercelular calcium waves in hippocampal slice cultures. J . Neurophysiol., 79:1045-1052.

Hassinger, T.D., Atkinson, P.B., Strecker, G.J ., Whalen, L.R., Dudek, F.E., Kossel, A.H., and Kater, S.B. (1995) Evidence for glutamatemediated activation of hippocampal neurons by glial calcium waves. J. Neurobiol., 28:159-170.

Hassinger, T.D., Guthrie, P.B., Atkinson, P.B., Bennett, M.V., and Kater, S.B. (1996) An extracellular signaling component in propagation of astrocytic calcium waves. Proc. Natl. Acad. Sci. U.S.A., 93:13268-13273.

J anigro, D., Gasparini, S., D' Ambroisio, R., Mckhann, G., and DiFrancesco, D. (1997) Reduction of K + uptake in glia prevents long-term depression maintenance and causes epileptiform activity. J. Neurosci., 17:2813-2824.

Karwoski, C.J., Lu, H.K., and Newman, E.A. (1989) Spatial buffering of light-evoked potassium increases by retinal Muller (glial) cells. Science, 244:578-580.

Kim, W.T., Rioult, M.G., and Cornell-Bell, A.H. (1994) Glutamateinduced calcium signaling in astrocytes. Glia, 11:173-184.

Kraig, R.P., Dong, L.M., Thisted, R., and J aeger, C.B. (1991) Spreading depression increases immunohistochemical staining of glial fibrillary acidic protein. J . Neurosci., 11:2187-2198.

Kristian, T., Gido, G., and Siesjo, B.K. (1993) Brain calcium metabolism in hypoglycemic coma.J . Cereb. Blood Flow Metab., 13:955-961. Largo, C., Tombaugh, G.C., Aitken, P.G., Herreras, O., and Somjen, G.G. (1997) Heptanol but not fluoroacetate prevents the propagation of spreading depression in rat hippocampal slices. J. Neurophysiol., 77:9-16.

Lauritzen, M. (1994) Pathophysiology of the migraine aura: The spreading depression theory. Brain, 117:199-210.

Lauritzen, M. and Fabricius, M. (1995) Real time laser-Doppler perfusion imaging of cortical spreading depression in rat neocortex. Neuroreport, 6:1271-1273.

Leao, A.A.P. (1944) Spreading depression of activity in cerebral cortex. J . Neurophysiol., 7:359-390. 
Lee, S.H., Magge, S., Spencer, D.D., Sontheimer, H., and Cornell-Bell, A.H. (1995) Human epileptic astrocytes exhibit increased gap junction coupling. Glia, 15:195-202.

Lucke, A., Kohling, R., Straub, H., Moskopp, D., Wassmann, H., and Speckmann, E.J . (1995) Changes of extracellular cal cium concentration induced by application of excitatory amino acids in the human neocortex in vitro. Brain Res., 671:222-226.

Nedergaard, M. (1994) Direct signaling from astrocytes to neurons in cultures of mammalian brain cells. Science, 263:1768-1771.

Nedergaard, M., Cooper, A.J ., and Goldman, S.A. (1995) Gap junctions are required for the propagation of spreading depression. J . Neurobiol., 28:433-444.

Newman, E.A. and Zahs, K.R. (1997) Calcium waves in retinal glial cells. Science, 275:844-847.

Odette, L.L. and Newman, E.A. (1988) Model of potassium dynamics in the central nervous system. Glia, 1:198-210.

Osipchuk, Y. and Cahalan, M. (1992) Cell-to-cell spread of calcium signals mediated by ATP receptors in mast cells. Nature, 359: 241-244.

Parpura, V., Basarsky, T.A., Liu, F., J eftinija, K., J eftinija, S., and Haydon, P.G. (1994) Glutamate-mediated astrocyte-neuron signalling [see comments]. Nature, 369:744-747.

Puka-Sundvall, M., Hagberg, H., and Andine, P. (1994) Changes in extracellular calcium concentration in the immature rat cerebral cortex during anoxia are not influenced by MK-801. Brain Res. Dev. Brain Res., 77:146-150.

Reichenbach, A. (1991) Glial K+ permeability and CNS K+ clearance by diffusion and spatial buffering. Ann. N.Y. Acad. Sci., 633:272-286.

Sanderson, M.J ., Charles, A.C., Boitano, S., and Dirksen, E.R. (1994) Mechanisms and function of intercellular calcium signaling. Mol. Cell Endocrinol., 98:173-187.

Sanderson, M.J ., Charles, A.C., and Dirksen, E.R. (1990) Mechanical stimulation and intercellular communication increases intracellular Ca2+ in epithelial cells. Cell Reg., 1:585-596.
Silver, I.A. and Erecinska, M. (1992) I on homeostasis in rat brain in vivo: Intra- and extracellular [Ca2+] and $[\mathrm{H}+]$ in the hippocampus during recovery from short-term, transient ischemia. J. Cereb. Blood Flow Metab., 12:759-772.

Sneyd, J ., Charles, A.C., and Sanderson, M.J . (1994) A model for the propagation of intercellular calcium waves. Am. J. Physiol., 266: C293-C302.

Sneyd, J., Wetton, B.T., Charles, A.C., and Sanderson, M.J . (1995) Intercellular calcium waves mediated by diffusion of inositol trisphosphate: A two-dimensional model. Am. J . Physiol., 268:C1537-C1545.

Somjen, G.G., Aitken, P.G., Czeh, G.L., Herreras, O., J ing, J ., and Young, J .N. (1992) Mechanism of spreading depression: A review of recent findings and a hypothesis. Can. J . Physiol. Pharmacol., 70 Suppl:S248-S254.

Takeda, M., Nelson, D.J ., and Soliven, B. (1995) Calcium signaling in cultured rat oligodendrocytes. Glia, 14:225-236.

Venance, L., Piomelli, D., Glowinski, J., and Giaume, C. (1995) Inhibition by anandamide of gap junctions and intercellular calcium signalling in striatal astrocytes. Nature, 376:590-594.

Venance, L., Stella, N., Glowinski, J ., and Giaume, C. (1997) Mechanism involved in initiation and propagation of receptor-induced intercellular calcium signaling in cultured rat astrocytes. J . Neurosci., 17:1981-1992.

Woods, R.P., I acoboni, M., and Mazziotta, J .C. (1994) Bilateral spreading cerebral hypoperfusion during spontaneous migraine headache. N. Engl.J . Med., 331:1689-1692.

Yuste, R., Nelson, D.A., Rubin, W.W., and Katz, L.C. (1995) Neuronal domains in developing neocortex: mechanisms of coactivation. Neuron, 14:7-17.

Zanotti, S.A. and Charles, A.C. (1997) Extracellular calcium sensing by glial cells-low extracellular calcium induces intracellular calcium release and intercellular signaling. J . Neurochem, 69:594-602. 